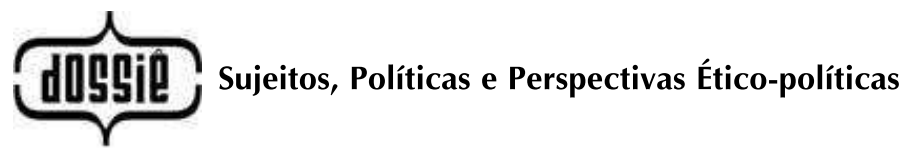

Fotografia: Sílvia Aguião. Parada do Orgulho LGBT do Rio de Janeiro, 2011.

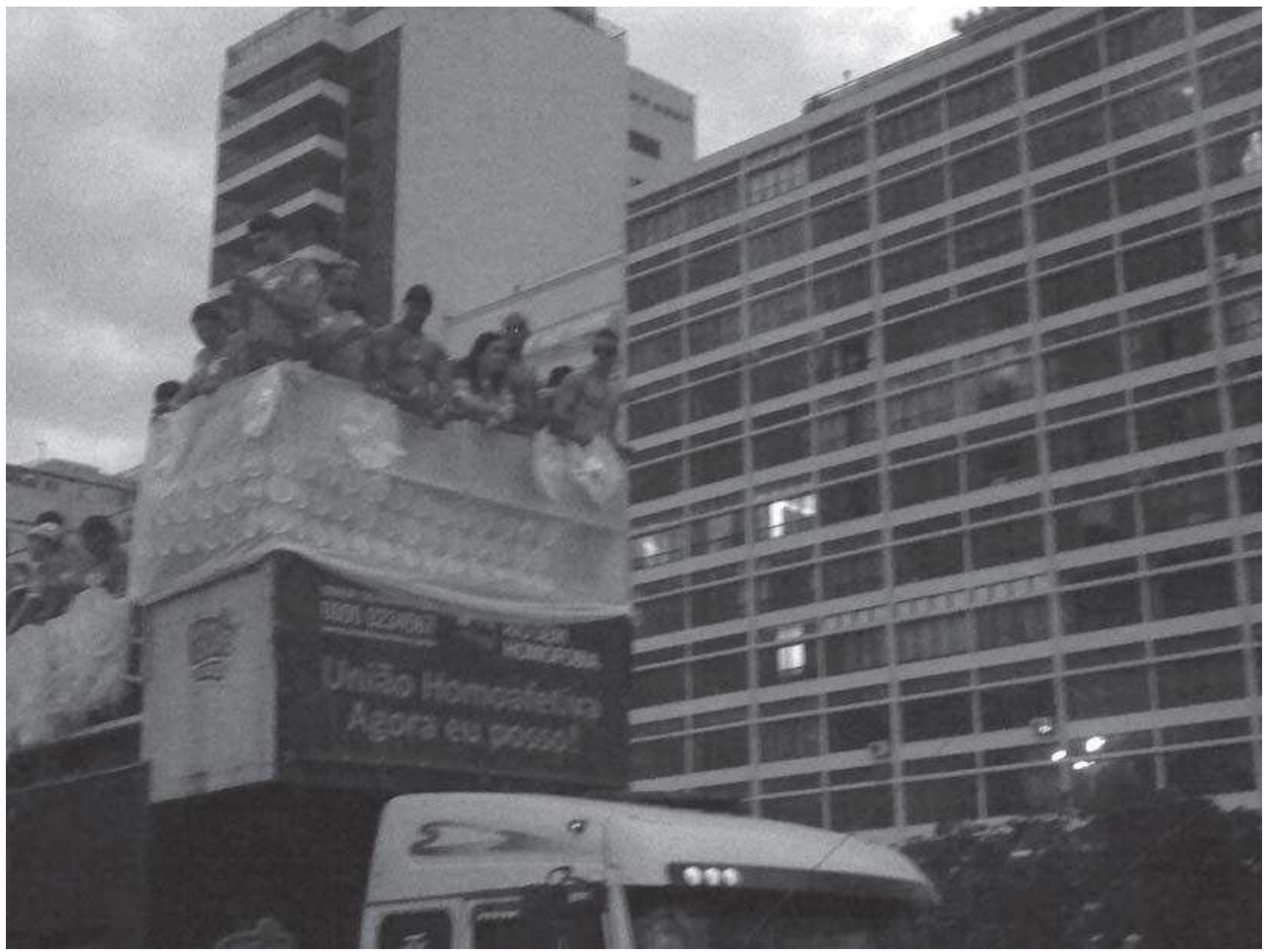




\title{
Diversidade sexual e Política Nacional de Saúde Mental: contribuições pertinentes dos sujeitos insistentes
}

\author{
Marco José de Oliveira Duarte*
}

\begin{abstract}
Resumo: O presente artigo tem como objetivo problematizar algumas questões pertinentes para os estudos em diversidade sexual, tendo como ponto de pauta as relações entre o sofrimento mental, os direitos humanos de LGBT e a política pública de saúde mental para contemporizar e qualificar o públicoalvo dos serviços de saúde mental. Toma como referência as representações sociais e culturais que instituíram esses sujeitos nos lugares próprios da patologia, do desvio, da segregação e da exclusão social e os atuais processos que se encontram na luta por direitos humanos e cidadania. Nesse contexto, apesar dos ditos avanços no campo dos direitos humanos, a experiência do sofrimento mental de LGBT é levada em consideração na perspectiva da promoção de equidade em saúde, a partir de suas vulnerabilidades específicas, mesmo sendo consenso no campo público e político da saúde, a necessidade de enfrentamento da homofobia e da transfobia.
\end{abstract}

Palavras-chave: Diversidade sexual; saúde mental; direitos humanos; análise qualitativa.

Abstract: This present article has as objective to promatize some pertinent
questions in studies of sexual diversity, using as the relations between staff
mental disorder, the LGBT's human rights and mental health public policy to
qualify to compromise the target audience of mental health services, by
reference to the social and cultural representations that these subjects have
established themselves in places of pathology, the deviation of segregacion
and social exlusion and the currente processes that are in the fight for human
rights and citizenship. In this context, said despite theadvances in the Field of
human rights, the experience LGBT's mental disorder are not taken into
account in view of promoting health equity from theis specific vulnerabilities,
even thoughconsensus in the field of health's public and political, coping
need to homophobia and transphobia. Keywords: Sexual diversity; mental health; human rights; qualitative analysis

\footnotetext{
* Assistente social, mestre em Serviço Social pela Escola de Serviço Social da Universidade Federal do Rio de Janeiro (ESS/UFRJ) e professor assistente da Faculdade de Serviço Social da Universidade do Estado do Rio de Janeiro (FSS/UERJ). E-mail: majodu@gmail.com
} 
Eu não espero pelo dia em que todos os homens concordem/ apenas sei de diversas harmonias bonitas possíveis sem juízo final (Caetano Veloso. Fora de Ordem. 1991)

O objetivo deste trabalho é contribuir com algumas questões pertinentes aos estudos em diversidade sexual, tendo como ponto de pauta as problematizações entre direitos humanos de lésbicas, gays, bissexuais, travestis e transexuais (LGBT) e a atual política de saúde mental para contemporizar uma nova demanda presente em nossa realidade social, bem como o alargamento da composição do públicoalvo dos serviços públicos que lidamos. São tomadas como referência as representações socioculturais que instituíram esses sujeitos nos lugares próprios da patologia, do desvio, da segregação e da exclusão social, e os atuais processos de afirmação das identidades LGBT na contemporaneidade.

Nesse contexto, apesar dos ditos avanços no campo dos direitos humanos e na consolidação da democracia, a experiência do sofrimento mental dos sujeitos LGBT, em seus processos de construção de identidades, que estão implicadas em operações ético-estéticas e biopolíticas, não é absorvida nem considerada na perspectiva da promoção de equidade em saúde, a partir de suas singularidades e, em particular, das suas vulnerabilidades específicas. Isso ocorre mesmo sendo consenso, no campo público e político da saúde e da educação, a necessidade de enfrentamento da homofobia e da transfobia no Sistema Único de Saúde (SUS).

\section{Diversidade sexual: enunciações de um campo}

Apesar de desejos e práticas sexuais sempre terem feito parte da vida humana, a ideia de sexualidade como um campo separado da vida das pessoas, que diz respeito ao prazer e aos desejos sexuais, é uma ideia recente na história humana, que surge dessa maneira apenas a partir do século XVIII (FOUCAULT, 1977).

A visão que define gênero como algo que as sociedades criam para significar as diferenças dos corpos sexualizados assenta-se em uma dicotomia entre sexos (natureza) versus gênero (cultura). Segundo essa visão binária, cada cultura moldaria e imprimiria suas marcas nesse corpo inerte e diferenciado sexualmente pela natureza. Ao contrário, segundo Butler (2003), podemos analisar gênero como uma sofisticada tecnologia social heteronormativa, operacionalizada pelas instituições médicas, linguísticas, domésticas, escolares e que produzem constantemente corposhomens e corpos-mulheres. Uma das formas de se reproduzir a heterossexualidade enquanto construção social consiste em cultivar os corpos em sexos diferentes, como aparências "naturais" e disposições heterossexuais naturais. Desta forma, a heterossexualidade constitui-se em uma matriz que conferirá sentido às diferenças entre os sexos.

Questões relativas à sexualidade, orientação sexual e as expressões das identidades de gênero que moldam os estudos no campo da diversidade sexual já são inumeráveis no que concerne às produções científicas de diversas áreas do conhecimento científico no Brasil e no exterior, ressaltando a crítica à ideologia heteronormativa/heterossexista. No entanto, apesar desse volume crescente, 


\section{hevista all pavtg}

\} DIVERSIDADE SEXUAL E POLÍTICA NACIONAL DE SAÚDE MENTAL - DUARTE, M. J. O. \}

percebemos uma lacuna entre esse material e as mudanças socioculturais, pedagógicas e sanitárias, salvo raras exceções, no que tange aos estigmas, preconceitos e discriminações à população LGBT.

Sabemos, no entanto, que as questões da marginalização, discriminação e estigmatização de LGBT são cotidianamente enfrentadas por estes cidadãos, seja em casos de desrespeito e violência; em situações vexatórias e preconceituosas; na destituição de esperanças de sobrevivência digna e segura; quando são comumente inferiorizados ou reprimidos ao assumirem uma identidade sexual fora dos padrões convencionais e heteronormativos; nos baixos índices de instrução (evasão escolar provocada pela discriminação); na dificuldade de acesso ao mercado de trabalho (subempregos e atividades estigmatizantes) e aos serviços de saúde, levando a população LGBT, em boa parcela, a um sofrimento psicossocial intenso, às vezes considerando-se anormal e desviante da normatividade dominante entre os sexos e gêneros. E há mesmo aqueles que, frente às suas angústias, medos e inseguranças, ou geram conflitos repressores de si, produzindo transtornos mentais de diversos tipos, ou apelam para saídas mais radicais, como o abuso de substâncias psicoativas ou a dependência química, a automutilação e até mesmo o suicídio.

Não podemos negar ou fazer vista grossa para as implicações éticas e políticas desses segmentos, em suas singularidades na realidade social, marcada pelas vulnerabilidades específicas, seja na luta pela equidade do acesso e da permanência no trabalho e emprego, seja na saúde e na educação. Mesmo que seja consenso que nos campos público e político haja a necessidade de enfrentamento da homofobia e da transfobia, pois são setores de sociabilidade e de políticas públicas, contraditoriamente também são lugares reprodutores da desigualdade, da segregação e da exclusão social, bem como da discriminação e do preconceito.

Dessa forma é necessário localizar os discursos da população em geral e em particular dos profissionais no campo da saúde, que muitas vezes reproduzem as relações de poder socialmente estabelecidas, que reforçam estereótipos e caricaturas que reduzem as singularidades e subjetividades da população LGBT. Decerto que a cultura midiática hegemônica, através das novelas, das propagandas, dos programas de TV etc., corrobora com a solidificação de modelos e conceitos sexistas, machistas, misóginos e homofóbicos que impõem aos LGBT limitações na livre expressão de suas identidades (FACCHINI, 2005), constituindo-se, portanto, flagrante violação da dignidade humana, incluindo seus direitos como cidadãos, por serem vistos com suas sexualidades pelo avesso. (BARBOSA; PARKER, 1999).

Desde 2010, na campanha eleitoral para presidente do país, assistimos à pauta moralista e conservadora de debates na esfera pública, seja pela temática da criminalização do aborto ou, em particular, no presente caso, pela intolerância com algumas bandeiras de luta do movimento LGBT, que muito tem se colocado na órbita pela criminalização da homofobia.

Neste ano, a temática da diversidade sexual tomou mais uma vez a mídia, principalmente, depois que a presidenta Dilma Rousseff suspendeu a distribuição do famoso "Kit Anti-homofobia" nas escolas, em "nome da moral e dos bons costumes". A questão da diversidade sexual, não é de hoje, vem tomando forma em debates, pesquisas e políticas, não só no campo governamental, mas também em 


\section{ReVistg all pgutg}

\} DIVERSIDADE SEXUAL E POLÍTICA NACIONAL DE SAÚDE MENTAL - DUARTE, M. J. O. \}

decorrência do aparecimento das próprias entidades LGBT. Ademais, vêm se expressando nos sindicatos e partidos políticos, na instituição dos setoriais LGBT, o que não existia até bem pouco tempo, quando o tratamento da questão era reduzido somente à Secretaria ou Departamento Feminino ou das Mulheres.

Assim, aquilo que até bem pouco tempo atrás era silenciado e invisível tornase público, sem conotação moral conservadora, e é investigado para proposituras políticas e públicas, sem preconceitos e discriminações. Desta forma, um conjunto de temas e questões relacionadas à população LGBT, tais como heteronormatividade, sexismo, homofobia, bullying, construção de identidades de gênero, sexualidade etc., tem que ser politizado, através do signo dos direitos humanos, da democracia, da liberdade e da emancipação humana.

A perseguição às lésbicas, aos gays, aos bissexuais, travestis e transexuais (LGBT) não é novidade, trata-se de um fenômeno observável há muito tempo. Apesar das novas identidades constituídas pela sociabilidade contemporânea para os velhos estereótipos e representações socioculturais de um passado não tão recente, "sapatão", "viado", "bicha", "gilete" e "boneca" são rotulações e discriminações para esses sujeitos que ainda persistem em viver de forma singular suas sexualidades, a despeito de insistirem em enquadrá-los no lugar próprio da patologia, do desvio, da segregação e exclusão social.

Muito desse discurso higiênico e moralista foi imposto não só pelo viés do conservadorismo da ordem médica - entendendo que a questão da orientação sexual foi retirada da tutela policial por afetar à ordem pública -, mas também pela esquerda stalinista no período pós-revolução bolchevique, quando muitos homossexuais foram exilados, mortos, ou presos e torturados, sob o rótulo de que se enquadravam no "desvio pequeno burguês" (OKITA, 1981) - como ainda se configurava até bem pouco tempo atrás na política cubana. Nesse ponto, o tratamento dado tanto por essa esquerda quanto pelo nazifascismo, com seus campos de concentração e o triângulo rosa como identificador desse público, está de igual forma violando os direitos humanos e a dignidade da pessoa humana, na medida em que hierarquizam e discriminam as orientações sexuais, como se houvesse uma referência ideal a ser seguida na vida pública e íntima dos sujeitos.

Nesse contexto, a luta pela garantia de direitos e das liberdades democráticas no limite do Estado burguês, apesar dos ditos avanços no campo dos direitos humanos e na consolidação da democracia no país, da experiência de visibilidade pública dos sujeitos LGBT, em seus processos de construção de identidades, de organização política e na construção de políticas públicas específicas e intersetoriais, tem sido alvo de inúmeros ataques na conquista do seu estatuto de cidadania, a exemplo das mulheres e negras/os.

Sabemos que boa parte dessa contestação no interior da sociedade tem sido mais radicalizada pelos setores conservadores e de forte teor fundamentalista religioso, impondo uma leitura de doença - como algo a ser tratado e a ser recuperado, como as "terapias reparadoras". Mesmo que os órgãos nacionais e internacionais que agregam a comunidade científica da área da saúde, como médicos, psiquiatras, psicólogos e assistentes sociais, tenham rompido com tal argumentação, os mesmos insistem na classificação das práticas sexuais atribuídas ao segmento LGBT na ordem 


\section{hevigta e PII paltg}

\} DIVERSIDADE SEXUAL E POLÍTICA NACIONAL DE SAÚDE MENTAL - DUARTE, M. J. O. \}

do pecado, com um tom de criminalização típico do moralismo eclesiástico e sua defesa dos bons costumes e de um tipo consagrado de família, a heterossexual, e seu modelo nuclear burguês. "Precisamos assegurar segurança (...) e direitos, valorizar os vários modos de ser homossexual, lutar contra o moralismo que diz que tudo é implicitamente negativo e pecaminoso" (SEFFNER, 2011, p. 67).

Ressaltamos também que muito dessa resistência conservadora deve-se a como os LGBT lidam com a questão da sexualidade, na sua forma livre de orientação sexual e na expressão das identidades de gênero. Isso só para citar algumas questões que por muito tempo se circunscreveram na ordem do privado - do interior da família, algo que diz respeito a cada um e, por isso, não sendo e não podendo estar no lugar da política e do público - , apesar de ser no espaço da rua que muitos(as) aprenderam suas formas de prazer, de gozo, de desejo, de sexo e sexualidade.

O que se percebe é que, quanto mais se avança nos direitos humanos LGBT, mais se apresentam também as formas discriminatórias e violentas, pela visibilidade no espaço democrático de diversos sujeitos e de suas formas de andar a vida. Desta forma, a radicalidade discriminatória, que se eleva à intolerância com os segmentos LGBT na sociedade, comumente chamadas de homofobia, lesbofobia, travestifobia e transfobia, tem suscitado nas gestões públicas, nos diversos setores e instâncias da administração pública, articulados ou não ao movimento social LGBT, a garantia de direitos e políticas públicas voltadas a essa população; mas isso não basta. É nesse contexto, em particular, que se observam significativas vitimizações na dinâmica social. Assim é que se instituem, a partir da esfera pública, seja municipal, estadual ou federal, os Centros de Referência de Promoção de Cidadania LGBT, que devem atuar de forma intersetorial com as políticas de saúde, e não só com as de educação e de assistência social, pois a garantia de direitos e a luta em favor da ética da diferença dar-se-á de forma coletiva e articulada.

\section{LGBT e Saúde Mental: dados e análises preliminares}

No relatório da pesquisa Diversidade sexual e homofobia no Brasil: intolerância e respeito às diferenças sexuais, publicado em 2009, sob coordenação da Fundação Perseu Abramo, em parceria com a Fundação Rosa Luxemburg Stiftung (RLS, Alemanha), há um levantamento quantitativo de abordagem domiciliar, com aplicação de questionários estruturados com 92 perguntas e amostragem de 2.014 entrevistas com população acima dos 15 anos de idade, envolvendo todas as classes sociais de 150 municípios (pequenos, médios e grandes) em 25 unidades federativas das cinco regiões do país (VENTURI et al, 2009).

A referida pesquisa, por sua abrangência e interesse investigativo, é pioneira no Brasil, pois revela indicadores objetivos para mensurar as práticas discriminatórias em razão da orientação sexual das pessoas. Diante disso, no Gráfico 1, observa-se, pelos dados sistematizados, que a quase totalidade da população afirma a existência de preconceito contra as pessoas LGBT. 
Gráfico 1: Existência de preconceito contra LGBT no Brasil

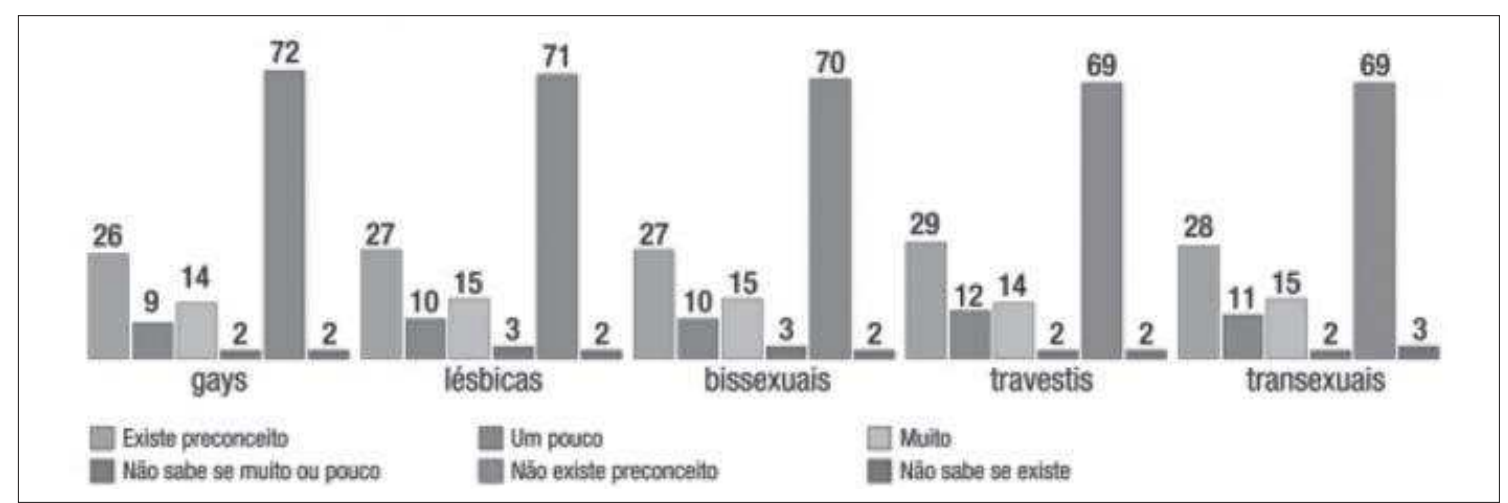

Fonte: VENTURI et al, 2009 (Relatório de Pesquisa "Diversidade sexual e homofobia no Brasil: intolerância e respeito às diferenças sexuais". São Paulo: Fundação Perseu Abramo, 2009).

Gráfico 2: Existência de preconceito pessoal contra LGBT

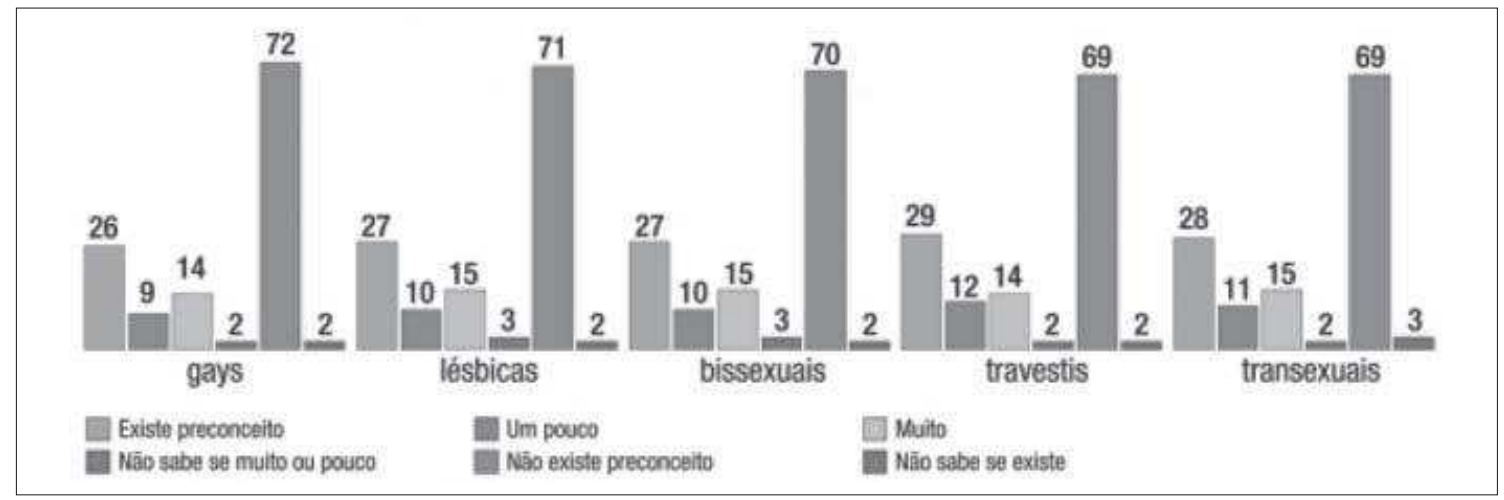

Fonte: VENTURI et al, 2009 (Relatório de Pesquisa "Diversidade sexual e homofobia no Brasil: intolerância e respeito às diferenças sexuais". São Paulo: Fundação Perseu Abramo, 2009).

De igual forma, no gráfico 2, que estabelece a existência de preconceito pessoal contra pessoas LGBT, podemos ressaltar uma taxa, que consideramos muito alta, entre os entrevistados ao apontarem o seu próprio preconceito em relação às pessoas LGBT, revelando, por si, a temática da homofobia. Estes resultados estão presentes nesse universo pesquisado e que retrata uma amostra significativa para $o$ contexto brasileiro.

Segundo os dados publicados no relatório da pesquisa Sexualidade, cidadania e homofobia, realizada pela Associação da Parada do Orgulho GLBT de São Paulo em parceria com a Secretaria Especial em Direitos Humanos da Presidência da República, durante a $10^{a}$ Parada do Orgulho GLBT de São Paulo (2006), 67 \% das pessoas daquela comunidade já sofreram algum tipo de discriminação em razão da orientação sexual e/ou identidade de gênero. E, acrescenta-se, dessas, 59\% afirmaram ter sofrido preconceito mais de uma vez. A pesquisa também mostrou que $32 \%$ dos entrevistados dizem que foram discriminados em ambientes formados por amigos ou vizinhos, $29 \%$ sofreram discriminação na escola ou faculdade, $26 \%$ em ambiente 


\section{hevista all pavtg}

\} DIVERSIDADE SEXUAL E POLÍTICA NACIONAL DE SAÚdE MENTAL - DUARTE, M. J. O. \}

familiar, 25\% foram discriminados em espaços comerciais ou de lazer, 21\% no ambiente de trabalho e $12 \%$ nos serviços de saúde. Isto aponta para uma dinâmica da violência em que as pessoas mais próximas a gays, lésbicas, bissexuais, transexuais e travestis cometem mais violência e discriminação. A pesquisa também apresentou dados em relação às agressões: 54\% dos entrevistados revelaram que já sofreram agressões verbais ou ameaças e $15 \%$ já foram agredidos fisicamente (FACCHINI; FRANÇA; VENTURI, 2007).

No Rio de Janeiro, por ocasião da 9a Parada do Orgulho GLBT (2004), houve também outra investigação, promovida pelo Grupo Arco-Íris de Conscientização Homossexual, em parceria com o Centro Latino-Americano em Sexualidade e Direitos Humanos da Universidade do Estado do Rio de Janeiro e o Centro de Estudos de Segurança e Cidadania da Universidade Cândido Mendes, publicada na forma de relatório de pesquisa, Política, direitos, violência e homossexualidade (CARRARA; RAMOS, 2005). Neste estudo é revelado que, de modo geral, a alta incidência de experiências de discriminações e de violências motivadas pela orientação sexual assevera a impressão de que a homofobia se reproduz de múltiplas formas - algumas mais sutis e outras mais abertas ou violentas - e em proporções muito significativas na nossa sociedade. Destas, surpreendentemente, o círculo de amigos e vizinhos $(33,5 \%)$ tem sua prevalência, seguido do ambiente familiar (27\%). A discriminação nas escolas e universidades, por parte de professores e colegas, vem logo em seguida, com uma incidência de $26,8 \%$. Os ambientes religiosos $(20,6 \%)$ e de lazer $(18 \%)$ vêm num segundo bloco, seguidos finalmente pelas discriminações no ambiente de trabalho e emprego (11,7\%) e no atendimento na área de saúde $(11,1 \%)$.

Comparativamente, as pesquisas realizadas - no Rio de Janeiro, em 2004, e a em São Paulo, em 2006 (CARRARA; RAMOS; SIMÕES, FACHINI, 2006) - revelam que os serviços de saúde e as relações com seus profissionais foram locais em que o(a)s entrevistado(a)s mesmo registrando menor freqüência de discriminações, também apontam a ocorrência. Nos relatórios das pesquisas afirma-se que nestes contextos, por um lado, o(a)s entrevistado(a)s menos assumiram sua orientação sexual, pois a omitem, e, por serviços, em decorrência dos efeitos acumulados pela presença da militância LGBT nas campanhas de prevenção de HIV/AIDS. Isso por terem sido sujeitos apontados, durante os anos 1980, como o "grupo de risco", basicamente em decorrência das suas práticas sexuais (discriminadas). E pode-se dizer que é nesse momento que a temática da diversidade sexual estreia no cenário das práticas de saúde em geral.

Temos observado, no entanto, em alguns serviços de saúde estudados, bem como em demandas propositivas nos espaços de controle social da saúde e de LGBT, que não é bem assim que as coisas têm acontecido nas práticas de cuidado e atenção na saúde, e em particular, na saúde mental. Se é verdade que a sociedade brasileira é preconceituosa com a população LGBT, e que as pessoas se identificam como preconceituosas com relação a esse segmento, de igual forma destacamos que a instituição da saúde, contraditoriamente, também o é:

Ao longo dos anos, desde 1988 e da implantação do SUS, houve muitos acertos em suas ações, mas também muitos obstáculos 
\} DIVERSIDADE SEXUAL E POLÍTICA NACIONAL DE SAÚDE MENTAL - DUARTE, M. J. O. \}

demarcados por cenas e discursos preconceituosos que, de acordo com níveis de intensidade distintos, discriminam, estigmatizam, violentam e excluem pessoas pelas mais variadas categorias, seja classe social, raça, etnia, identidade de gênero, orientação sexual, relação intergeracional ou estética corporal (PERES, 2010, p. 309).

Para começo de conversa, registra-se que, pioneiramente, o governo federal elaborou dois documentos oficiais para o trato com essa questão, a saber:

a) Plano Nacional de Promoção da Cidadania e Direitos Humanos LGBT de 2009, que é oriundo das propostas aprovadas na plenária final da I Conferência Nacional de LGBT, em 2008. Das 559 propostas consolidadas no Relatório Final, 167 correspondem à área da saúde. No referido documento, temos um total de 166 estratégias de ação, destas, 48 dizem respeito ao campo da saúde.

b) Política Nacional de Saúde Integral de LGBT de 2010, que pela sua consistência programática, destacamos que
A Política (Nacional de Saúde Integral de) LGBT tem como marca o reconhecimento dos efeitos da discriminação e da exclusão no processo de saúde-doença da população LGBT. Suas diretrizes e seus objetivos estão, portanto, voltados para mudanças na de- terminação social da saúde, com vistas à redução das de- sigualdades relacionadas à saúde destes grupos sociais (BRASIL, 2010 b, p. 4).

Desta forma, cabe ressaltar que as ações de saúde, contidas no plano acima, estão inseridas na Política Nacional de Saúde Integral de LGBT e que essas políticas têm como diretriz a perspectiva de eliminar a discriminação e a marginalização. Todavia, essas políticas só foram possíveis em decorrência de duas grandes instituições, uma delas foi o Programa Nacional Brasil Sem Homofobia (BSH), em 2004, que:

De um total de 53 ações previstas no BSH, três integram o tópico Direito à Saúde: consolidando um atendimento e tratamentos igualitários (BRASIL, 2004). A principal delas talvez seja a formalização do Comitê Técnico 'Saúde da População de Gays, Lésbicas, Transgêneros e Bissexuais', do Ministério da Saúde, com o objetivo de estruturar uma Política Nacional de Saúde para essa população. As outras duas ações dizem respeito, (...) à produção de conhecimento sobre saúde da população BLGT e à capacitação de profissionais de saúde para o atendimento a essa população. Ainda em 2004, é formalizado o referido Comitê 


\section{hevista all pavtg}

\} DIVERSIDADE SEXUAL E POLÍTICA NACIONAL DE SAÚDE MENTAL - DUARTE, M. J. O. \}

(...) que tem por atribuição fomentar uma política de âmbito nacional (MELLO, 2010, p. 8).

A outra situa o Brasil signatário dos Princípios de Yogyakarta (2006). No entanto, mesmo com o Estado brasileiro reconhecendo essa necessidade, podemos afirmar que essa resposta foi dada a partir da demanda dos movimentos organizados de LGBT e suas reivindicações por direitos civis, políticos, sociais e humanos.

Dentro deste contexto, Mello (2010) aponta uma lista de documentos oficiais que não tratam exclusivamente da questão da saúde LGBT, mas que sinalizam proposições para esse público, tais como: o Relatório Final da $13^{\circ}$ Conferência Nacional de Saúde (2007), o Programa Nacional de Direitos Humanos 2ำ e $3^{\circ}$ (PNDH), a Política Nacional de Atenção Integral à Saúde da Mulher e a Política Nacional de Atenção Integral à Saúde do Homem. O autor destaca a criação da Comissão Intersetorial de Saúde da População LGBT, no âmbito do Conselho Nacional de Saúde, e nesta direção é que a Política Integral de Saúde da População LGBT foi aprovada pelo Conselho Nacional de Saúde (CNS), em 2009. Todavia, a mesma continua restrita ao papel, tendo em vista que é absolutamente recente a sua pactuação pela Comissão Intergestores Tripartite ${ }^{1}(\mathrm{CIT})$ e ainda se processam articulações para sua efetiva implementação entre gestores, trabalhadores e usuários LGBT, como a recente reativação do Comitê Técnico de Saúde Integral de LGBT. Este é composto por representantes das secretarias do Ministério da Saúde e órgãos afins, assim como por representantes da sociedade civil e pesquisadores(as), no sentido de acompanhar, monitorar e avaliar com dados precisos a implantação e a implementação dessa política.

É neste contexto que as demandas e questões do movimento LGBT, tais como união/casamento civil entre pessoas de mesmo sexo (casamento igualitário); contrato de união estável (agora com o reconhecimento de unidade familiar pelo Supremo Tribunal Federal das famílias homoconjugais, a partir da concepção de homoafetividade e direitos homoafetivos); homoparentalidade; adoção de filhos; doação de sangue; reprodução assistida; serviço militar; planos de saúde conjuntos; declaração conjunta de imposto de renda; heranças e sucessões; redução da violência e dos assassinatos; garantia dos direitos sexuais e reprodutivos; direito ao uso do nome social;processo transexualizador no SUS (ARÁN, MURTA e LIONÇO, 2009) e luta pela criminalização da homofobia (PLC 122/06), entre outras situações de desigualdades de direitos, passam a compor o conjunto das agendas políticas, governamentais, jurídicas e legislativas.

Quando pensamos na saúde mental da população LGBT, identificamos a relação entre a cultura homofóbica e o alto índice de suicídio e de sofrimento psíquico entre os jovens LGBT, privilegiadamente. Isso é decorrente da própria dinâmica do sofrimento, derivado da incorporação por esses jovens da homofobia presente na sociedade e nas instituições - homofobia institucionalizada, quando os mesmos ad-

\footnotetext{
1 A CIT é uma Comissão que reúne representantes de gestores de saúde municipais, estaduais e federais, para a definição das responsabilidades e atribuições de todas as esferas de gestão no âmbito do SUS. Em 06/12/2011, foi divulgada a Resolução do Ministério da Saúde n.2, que publicizou a decisão da CIT de pactuação desta Política.
} 


\section{ReVistg all pgutg}

\} DIVERSIDADE SEXUAL E POLÍTICA NACIONAL DE SAÚDE MENTAL - DUARTE, M. J. O. \}

quirem uma autopercepção negativa de si mesmos e baixa autoestima. Temos observado uma nova tendência, significativa, mas não organizada, de segmentos LGBT, em particular na juventude, de se assumirem e de se identificarem como LGBT na contramão das opressões e dos preconceitos, e são os que se colocam como resistentes e, ao mesmo tempo, alvo dos ataques homofóbicos mais radicais, que levam, frequentemente, ao assassinato desses sujeitos. Acrescenta-se que é essa mesma juventude (entendendo aquela que ainda não completou a maioridade legal, ou seja, os adolescentes) que se destaca no topo das taxas de homicídio, qualificadas também por cor, raça, classe, sexo, orientação sexual e identidade de gênero.

É certo afirmar que a epidemia de HIV/AIDS possibilitou-nos a quebra de paradigmas biomédicos na abordagem da saúde da população LGBT. Ou seja, nos fez apreender outra relação profissional-usuário, a inter-relação entre promoção da saúde e de outros direitos humanos, incluindo a diversidade sexual e o papel dos fatos socioculturais, como o estigma/preconceito na adoção de cuidados à saúde e na possibilidade de adoecimento. Levou-nos ainda a entender que a ação do profissional de saúde é uma relação pedagógica e emancipatória, em que tanto profissional quanto usuários são sujeitos, em que o diálogo e a colaboração são fundamentais e os significados do processo saúde-doença devem ser negociados e conversados. Em consequência, entende-se que a saúde de qualquer sujeito, independente da sua sexualidade e das identidades de gênero, não pode ficar restrita à abordagem reducionista da sua saúde sexual.

Nesta direção, ao tomarmos, principalmente a Lei 10.216/2001, que institui a nova Política Nacional de Saúde Mental, verificamos que a denominação "doente mental" não existe mais, sendo substituída por "pessoa portadora de transtorno mental", significando o lugar da cidadania deste usuário. E, em particular, observase que esse entendimento da loucura rompe com os paradigmas biomédicos psiquiátricos, com a lógica do tratamento medicamentoso em si e com a centralidade do modelo hospitalocêntrico-manicomial.

Ao tomarmos a saúde mental de LGBT, , no referido documento oficial a respeito, a temática aparece, no entanto, relacionada à lógica das perturbações mentais. E isto seja quando diz respeito "à depressão, às crises de ansiedade e sensações de pânico que parecem ser frequentes entre as travestis" (BRASIL, 2010, p.11), seja quando dos objetivos específicos de tal política, cujo foco é "reduzir os problemas relacionados à saúde mental, drogadição, alcoolismo, depressão e suicídio entre LGBT, atuando na prevenção, promoção e recuperação da saúde" (op. cit., p. 18). O mesmo documento, na parte relacionada às responsabilidades e atribuições relacionadas à política, define com uma das ações do Ministério da Saúde para a população LGBT na relação com a saúde mental "implementar ações e práticas educativas em saúde nos serviços do SUS, com ênfase na promoção da saúde mental, orientação sexual e identidade de gênero" (op. cit., p. 19).

Independente disso, contudo, o profissional de saúde mental, no cotidiano do cuidado aos usuários LGBT nos serviços de saúde, deve promover o respeito às diferenças singulares como princípio ético imanente da condição humana, e, por isso, as mesmas não podem ser usadas como instrumento de reprodução dos tratamentos desiguais e discriminatórios. Não é por acaso que a expressão integral 


\section{hevistg e.tI paUtg}

\} DIVERSIDADE SEXUAL E POLÍTICA NACIONAL DE SAÚDE MENTAL - DUARTE, M. J. O. \}

aparece no texto oficial, na medida em que se relaciona com um dos princípios caros ao SUS, a integralidade do cuidado.

As questões da escuta, do acolhimento, do território, da subjetividade, do afeto, da responsabilização, da referência e da ética de respeito à diferença, que são operações ético-estéticas e políticas, se articulam aos princípios do SUS e da Reforma Psiquiátrica, em particular, na integralidade do cuidado, tomando o(a) usuário(a) como cidadão portador de direitos.

De igual sentido, observa-se a dissolução da concepção de patologia, desvio, distúrbio ou perversão para a orientação sexual, como se tivesse algo a consertar ou a punir, quando das deliberações dos conselhos profissionais de medicina (1985), psicologia (1999) e serviço social (2006) no Brasil. E também da Organização Mundial da Saúde (OMS), em 17 de maio de 1990, quando da retirada do termo "homossexualismo" da Classificação Internacional de Doenças (CID), a exemplo da Associação Americana de Psiquiatria, que em 1973 retirou essa patologia do Manual Diagnóstico e Estatístico de Transtornos Mentais (DSM-4). Um exemplo que, em 1975, foi seguido pela Associação Americana de Psicologia, pelo entendimento, para esses organismos nacionais e internacionais, de que a diversidade sexual é constitutiva do campo dos direitos sexuais e humanos.

Dessa forma, quando tratamos das instituições da saúde por uma ética da diferença, pelo signo da diversidade e pela garantia dos direitos, as nossas práticas sócio-sanitárias não se limitam aos muros de qualquer serviço de saúde, seja ele um hospital, um centro de saúde, uma unidade básica ou mesmo uma equipe da Estratégia de Saúde da Família (ESF) ou do Centro de Atenção Psicossocial (CAPS). Isto é, reside aí também a tomada de responsabilidade por parte das mesmas, com o rompimento e a desconstrução de uma política ou uma ordem instituída que exclui e discrimina LGBT - e não exclusivamente.

Essas formas discriminatórias de lidar com a diferença apresentam-se de múltiplas maneiras no cotidiano dos serviços de saúde, como, por exemplo, quando se deixam manifestar, de qualquer modo, palavras ofensivas e chulas dirigidas a pessoas LGBT, ou mesmo quando acontecem equiparações de humanos com animais; quando se estabelece a questão da orientação sexual como critério, seja para o que for; quando se impede o debate livre, democrático e fraterno sobre a liberdade de orientação sexual, a discriminação por identidade e expressão de gênero, no sentido de mostrar que a homossexualidade e a transexualidade ${ }^{2}$ não são doenças; quando não se impede ato de violência física motivado por atos de discriminação, assim como de constrangimento físico; quando se deixa que qualquer grupo, organização ou movimento afirme, divulgue e apoie valores de homofobia que vão contra os valores civilizatórios da modernidade.

Desta forma, os serviços públicos, em particular os de saúde, não estão isolados e imunes a essas questões e, justamente por serem espaços de encontro entre sujeitos, também se tornam lugar de disputas e de enfrentamentos, no campo das

\footnotetext{
${ }^{2}$ A transexualidade, ao contrário da homossexualidade, permanece na classificação da OMS e na compreensão de outras associações normatizadoras das ações de saúde descrita como "transexualismo" e associada à ideia de transtorno mental (Cf. ARÁN, MURTA;LIONÇO, 2009).
} 


\section{ReVistg all pgutg}

\} DIVERSIDADE SEXUAL E POLÍTICA NACIONAL DE SAÚdE MENTAL - DUARTE, M. J. O. \}

ideias e dos projetos políticos - particularmente quando se trata da temática da diversidade sexual e suas discriminações correlatas.

Podemos demonstrar a situação: quando uma usuária ou profissional de saúde travesti usa seu nome social, "Bianca", por exemplo, e não o que está na sua certidão de nascimento ou registro civil, determinado pelo seu sexo biológico,"João". É como Bianca que deve ser tratada, seja na hora da "chamada", na recepção ou no atendimento em consultório ou na forma de uma visita domiciliar, numa reunião da equipe de trabalho, ou mesmo em um setor administrativo de uma organização de saúde qualquer, e quando usa o banheiro (sem se submeter aos olhares reprovadores de sua circulação no ambiente hospitalar. Na sala de espera ou no setor administrativo dos serviços de saúde frequentemente tais sujeitos resistem às famosas "piadinhas" preconceituosas e estereotipadas dirigidas à população LGBT em geral, e em especial a travestis e transexuais. Somam-se, nesse contexto, os tantos outros registros violentos que transitam em nossa cultura e sociedade e que marcam esses sujeitos ou os aniquilam.

Ao analisarmos o Relatório Final da IV Conferência Nacional de Saúde Mental - intersetorial (2010) e o conjunto dos documentos do campo LGBT (a Política Nacional de Saúde Integral de LGBT e o Plano Nacional de Promoção da Cidadania e Direitos Humanos $\mathrm{LGBT}^{3}$ ), elaboramos quadros comparativos para adensar nossa análise comparativa das políticas públicas LBGT e de Saúde Mental.

Desta forma, a temática da formação e educação permanente para os profissionais da saúde (Quadro 1) tem maior destaque e demanda por parte da população LGBT, embora também seja apresentada pelo campo da Saúde Mental. Cabe destacar que, nestes espaços, a participação dos movimentos sociais LGBT na esfera pública de controle social das políticas se faz presente. Assim, torna-se uma forma de reconhecer e erradicar as práticas e os efeitos perversos dos processos de discriminação e de exclusão sobre a saúde e o cotidiano dos serviços e pauta a necessidade de capacitação dos profissionais para o atendimento ao público LGBT, no sentido de reverter certas práticas pela aquisição de novos conhecimentos.

É interessante observar que, no quadro dos conselhos profissionais da área da saúde, existem outras categorias profissionais que ainda não se pronunciaram frente às práticas discriminatórias com a população LGBT, incluindo aí também os próprios profissionais que se vinculam a esse segmento populacional, no sentido de dar uma orientação aos mesmos. Nesse sentido, arrolamos, dentre as profissões de saúde reconhecidas pelo Ministério da Saúde, as que não apresentam deliberações ou resoluções específicas para esse público: enfermagem, fisioterapia, terapia ocupacional, odontologia, medicina veterinária, biologia, educação física, biomedicina, farmácia, nutrição, fonoaudiologia e química.

\footnotetext{
${ }^{3}$ De forma sistematizada e mantendo sua unidade propositiva através do documento Texto-Base da II Conferência Nacional LGBT (2011), elaborado pelo Conselho Nacional LGBT da Secretaria Especial de Direitos Humanos da Presidência da República (2011), ainda na versão para discussão, tendo em vista a realização da mesma em dezembro de 2011.
} 


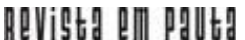

\} DIVERSIDADE SEXUAL E POLÍTICA NACIONAL DE SAÚDE MENTAL - DUARTE, M. J. O. \}

Quadro 1 - Comparativo entre políticas públicas LGBT e de Saúde Mental, segundo a temática da formação e educação permanente

para os profissionais da saúde

\begin{tabular}{|c|c|}
\hline Política de Saúde LGBT (2008) & Politica de Saúde Mental (2010) \\
\hline $\begin{array}{l}\text { "1- Sensibilizar e capacitar as equipes profissionais } \\
\text { do Programa de Saúde da Mulher para a atenção } \\
\text { às especificidades no atendimento às lésbicas, } \\
\text { mulheres bissexuais e transexuais, nos estados e } \\
\text { municipios." } \\
\text { "3- Implementar nas instituições formadoras de } \\
\text { recursos humanos iniciativas visando à inclusão } \\
\text { dos conteúdos relacionados à saúde de Lésbicas, } \\
\text { Gays, Bissexuais, Travestis e Transexuais nos } \\
\text { processos de Educação Permanente em Saúde } \\
\text { para os profissionais da área." } \\
\text { "4- Promover e apoiar a inclusão dos temas } \\
\text { direitos sexuais e reprodutivos, doenças } \\
\text { sexualmente transmissiveis e HIV/AIDS em } \\
\text { oficinas e atividades de informação, formação, } \\
\text { mobilização de instituições e espaços de atuação } \\
\text { com os setores que trabalham com pessoas com } \\
\text { deficiência e a população LGBT." } \\
\text { "5- Incluir o tema da Saúde Integral de Lésbicas, } \\
\text { Gays, Bissexuais, Travestis e Transexuais nos } \\
\text { processos de formação e educação permanente } \\
\text { dos trabalhadores da saúde." } \\
\text { " } 22 \text { - Garantir a criação e divulgação de uma } \\
\text { cartilha sobre a Saúde de LGBT contendo } \\
\text { informações sobre a rede de saúde do SUS." } \\
\text { "31-Promover, na rede de atendimento à saúde } \\
\text { mental, estudos e pesquisas para a produção de } \\
\text { indicadores e intervenções especificos/as dos/as } \\
\text { usuários/as de álcool e drogas na população } \\
\text { LGBT." } \\
\text { "34- Apoio à realização de estudos e pesquisas } \\
\text { para a produção de conhecimento em saúde de } \\
\text { Lésbicas, Gays, Bissexuais, Travestis e } \\
\text { Transexuais." } \\
\text { "44- Sugerir a inclusão das temáticas de } \\
\text { orientação sexual e identidade de gênero aos } \\
\text { conselhos de profissionais de saúde." }\end{array}$ & $\begin{array}{l}\text { "240. Desenvolver e divulgar estudos e pesquisas } \\
\text { acerca da saúde mental da população LGBT } \\
\text { (Lésbicas, Gays, Bissexuais, Travestis e } \\
\text { Transexuais), e os impactos das violências em } \\
\text { detrimento das opressões das orientações sexuais } \\
\text { e identidades de gênero diversas dos } \\
\text { padrões/referências historicamente impostas." } \\
\text { "791. Incluir tema dos direitos das pessoas LGBT } \\
\text { (Lésbicas, Gays, Bissexuais, Travestis e } \\
\text { Transexuais) nos cursos de formação dos } \\
\text { trabalhadores em saúde mental." }\end{array}$ \\
\hline
\end{tabular}

Fonte: NEPS-FSS/UERJ4.

Outra temática que salta aos olhos no processo de análise é a que se relaciona ao combate ao estigma e ao respeito à diferença e à diversidade, bem como à justiça e ao sistema de garantia de direitos sociais e civis e à cidadania. Esta se coloca na chave genérica denominada de direitos humanos e saúde mental (Quadro 2),

\footnotetext{
${ }^{4}$ Para maior detalhamento conferir, respectivamente, os documentos Brasil (2010a) e Brasil (2010b).
} 


\section{ReVistg all pgutg}

\} DIVERSIDADE SEXUAL E POLÍTICA NACIONAL DE SAÚDE MENTAL - DUARTE, M. J. O. \}

embasada pelas expressões e reivindicações da população LGBT em suas proposições, tanto em um campo quanto no outro. Essa temática/demanda é melhor sistematizada pelo relatório da política de saúde mental, a nosso ver, pela presença militante também dos usuários do Movimento Nacional da Luta Antimanicomial (DUARTE, 2010), que arduamente encontram-se na dobra histórica da saúde mental e dos direitos humanos.

Quadro 2 - Comparativo entre políticas públicas LGBT e de Saúde Mental, segundo a temática dos direitos humanos e saúde mental

\begin{tabular}{|c|c|}
\hline LGBT (2008) & Saúde Mental (2010) \\
\hline 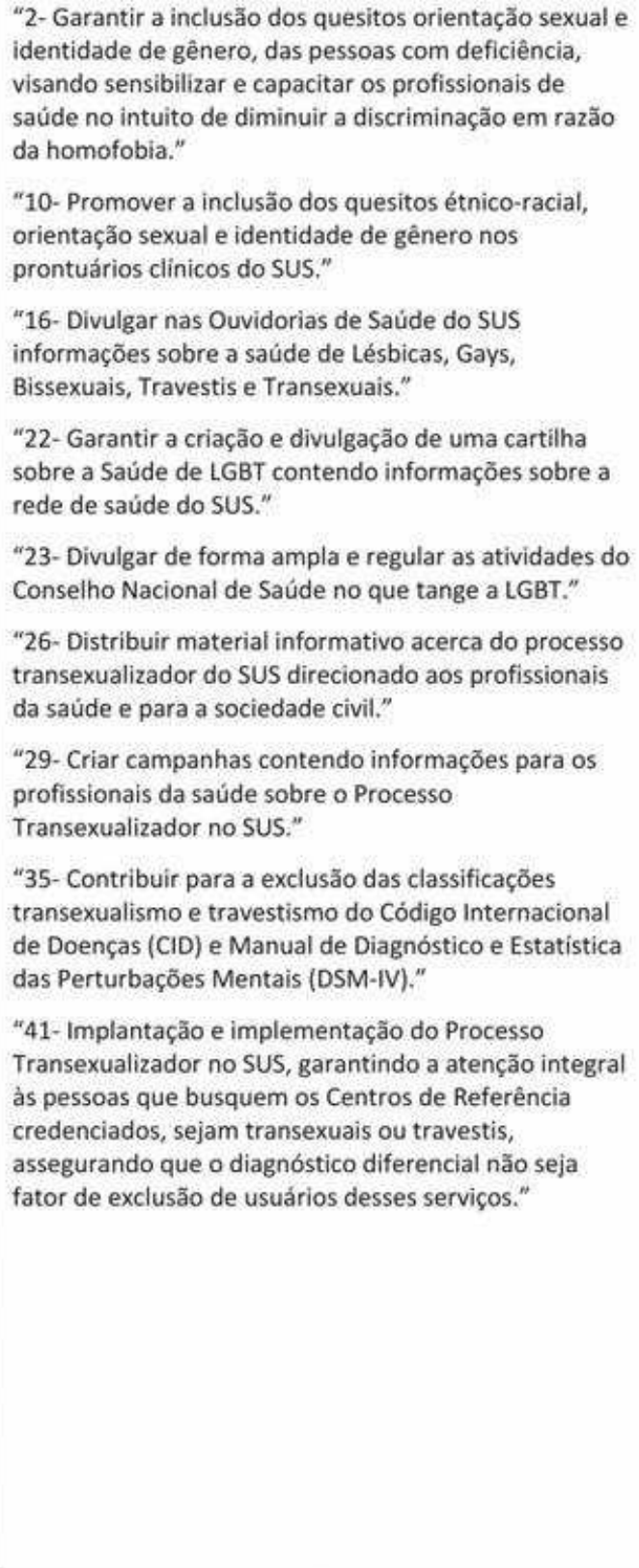 & 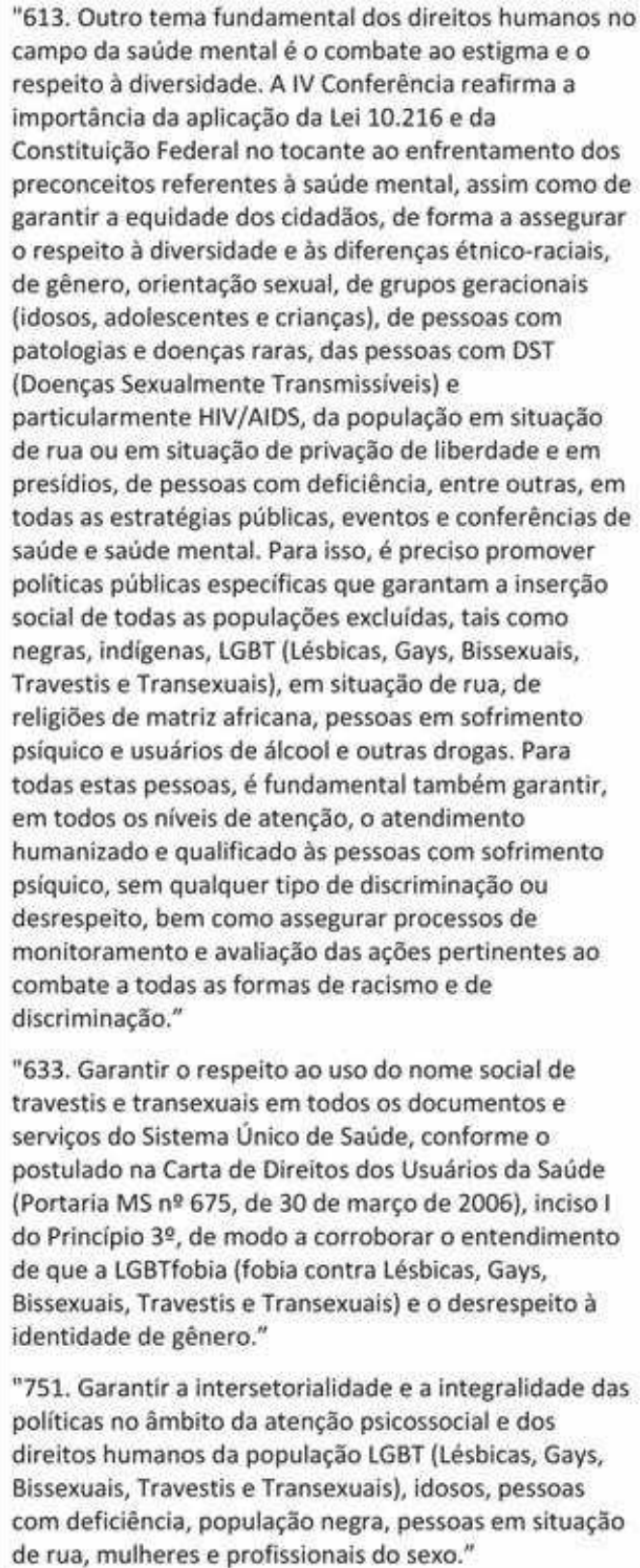 \\
\hline
\end{tabular}

Fonte: NEPS-FSS/UERJ. 


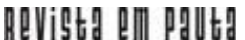

\} DIVERSIDADE SEXUAL E POLÍTICA NACIONAL DE SAÚDE MENTAL - DUARTE, M. J. O. \}

Pela mesma intencionalidade propositiva, a temática da violência e saúde mental (Quadro 3) tem nuances diferenciadas, mas, de igual forma, denuncia-se e apela-se para que haja redução das desigualdades motivadas por orientação sexual e identidade de gênero, assim como se luta pelo combate à homofobia, lesbofobia e transfobia, e a discriminação nas instituições e serviços do SUS, como agravantes do sofrimento desta população no âmbito da sociedade em geral).

Quadro 3 - Comparativo entre políticas públicas LGBT e de Saúde Mental, segundo temática da violência e saúde mental

\begin{tabular}{|c|c|}
\hline LGBT (2008) & Saúde Mental (2010) \\
\hline $\begin{array}{l}\text { "30- Realizar campanha de enfrentamento da } \\
\text { homofobia, lesbofobia, transfobia e demais } \\
\text { formas de discriminaçăo e violência contra } \\
\text { Lésbicas, Gays, Bissexuais, Travestis e Transexuais } \\
\text { no SUS." } \\
\text { "36-Criar uma interface entre a Ouvidoria do SUS, } \\
\text { o Centro de Referência pelos Direitos Humanos } \\
\text { LGBT-CRLGBT e/ou coordenadoria municipal } \\
\text { (quando houver) pelos direitos LGBT e a } \\
\text { Corregedoria do Municipio, visando a parcerias no } \\
\text { intuito de tratar demandas de denúncia de } \\
\text { violência, agressão e discriminação contra LGBT } \\
\text { nos serviços de saúde." }\end{array}$ & $\begin{array}{l}\text { "987. Para isso, é enfatizada a importância de } \\
\text { sensibilizar a população sobre os novos } \\
\text { paradigmas em saúde mental e da cultura da paz, } \\
\text { promovendo um amplo debate com a sociedade, } \\
\text { tematizando a não violência e a não discriminação } \\
\text { e estigmatização das pessoas em sofrimento } \\
\text { psíquico e seus familiares, ou com uso prejudicial } \\
\text { de álcool e outras drogas, e estimulando } \\
\text { estratégias de luta contra a violência e a exclusão } \\
\text { social vivenciados por elas. } \\
\text { "1013. Garantir a sensibilização de gestores e } \\
\text { trabalhadores da saúde para implantação da } \\
\text { política de saúde LGBT como forma de } \\
\text { enfrentamento da LGBTfobia (fobia de Lésbicas, } \\
\text { Gays, Bissexuais, Travestis e Transexuais) e como } \\
\text { forma de diminuir o sofrimento psíquico desta } \\
\text { população afetada pelo preconceito e pela } \\
\text { discriminação constitui importante fator de } \\
\text { vulnerabilizacão em Saúde Mental." }\end{array}$ \\
\hline
\end{tabular}

Fonte: NEPS-FSS/UERJ.

Uma temática comum diz respeito também à questão da acessibilidade dos usuários LGBT no SUS (Quadro 4), isto é, à garantia de seu acesso à Saúde e Saúde Mental. Nessa temática, considera-se a orientação sexual e a identidade de gênero como determinantes sociais da saúde e as desfavoráveis condições de saúde da po-pulação LGBT, visando à eliminação das iniquidades e desigualdades em saúde e o enfrentamento de outros condicionantes sociais para este grupo populacional na determinação da saúde mental destes sujeitos em particular.

Podemos aferir que em ambas as políticas - LGBT e Saúde Mental - há di-retrizes voltadas para a promoção da equidade em saúde. No entanto, cabe sinalizar que, embora políticas instituídas, a temática da saúde LGBT deve ser articulada pelo Ministério da Saúde para que seja implementada.

\section{Considerações Finais}

No presente artigo indicamos a necessidade imperiosa da proteção e do res-peito ao direito à sexualidade, à orientação sexual e às expressões da identidade de gênero 


\section{ReVisto pII pgutt}

\} DIVERSIDADE SEXUAL E POLÍTICA NACIONAL DE SAÚDE MENTAL - DUARTE, M. J. O. \}

Quadro 4 -- Comparativo entre políticas públicas LGBT e de Saúde Mental, segundo temática da acessibilidade dos usuários LGBT ao SUS

\begin{tabular}{|c|c|}
\hline LGBT (2008) & Saúde Mental (2010) \\
\hline $\begin{array}{l}\text { "6- Ampliar e qualificar a atenção básica no } \\
\text { cuidado aos idosos Lésbicas, Gays, Bissexuais, } \\
\text { Travestis e Transexuais, dando continuidade ao } \\
\text { processo de implantação e implementação da } \\
\text { Caderneta de Saúde da Pessoa Idosa e a atenção } \\
\text { domiciliar humanizada, em consonância com as } \\
\text { diretrizes da Política Nacional de Atenção à Saúde } \\
\text { da Pessoa Idosa." } \\
\text { "8- Reconhecer e incluir nos sistemas de } \\
\text { informação do SUS e no planejamento familiar, } \\
\text { todas as configurações familiares protagonizadas } \\
\text { por lésbicas, gays, bissexuais, travestis e } \\
\text { transexuais, com base na desconstrução da } \\
\text { heteronormatividade." } \\
\text { "Qualificar a atenção à saúde mental em todas as } \\
\text { fases de vida de Lésbicas, Gays, Bissexuais, } \\
\text { Travestis e Transexuais com o objetivo de prevenir } \\
\text { os agravos decorrentes dos efeitos da } \\
\text { discriminação e reduzir os danos decorrentes do } \\
\text { uso abusivo de álcool e outras drogas." } \\
\text { "24- Garantir a atenção à saúde mental da } \\
\text { população LGBT em decorrência dos efeitos } \\
\text { colaterais frente ao uso dos antirretrovirais." }\end{array}$ & 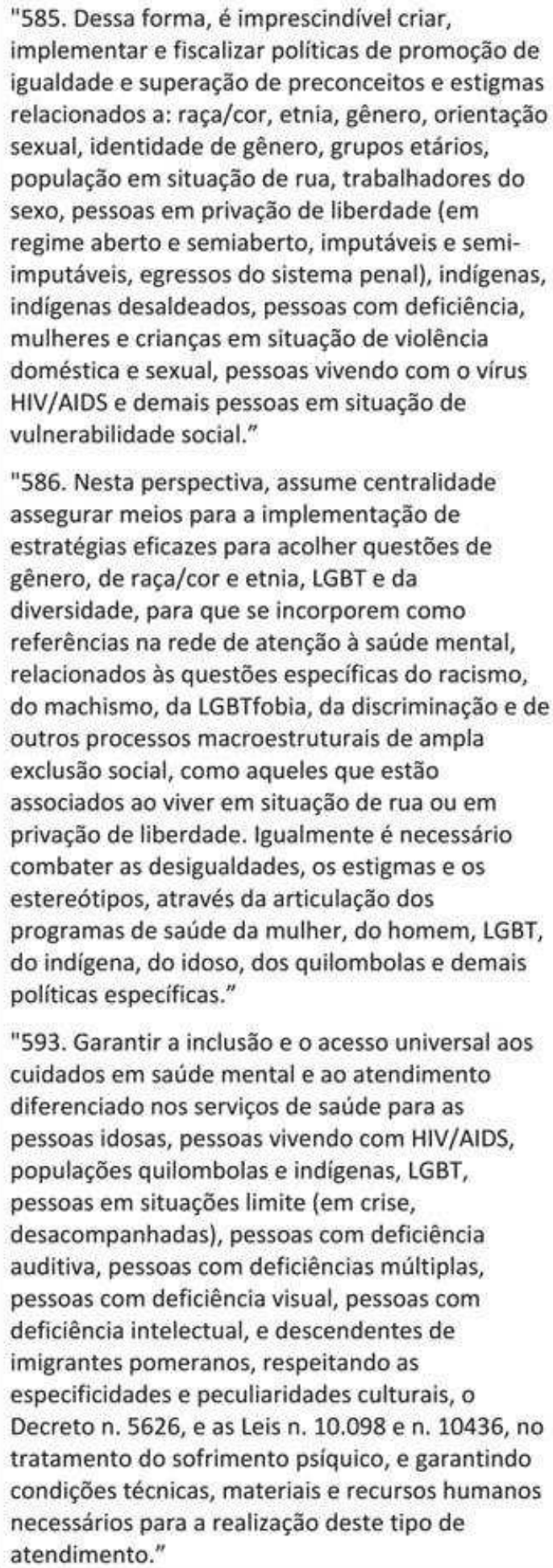 \\
\hline
\end{tabular}

Fonte: NEPS-FSS/UERJ. 


\section{hevista all pavtg}

\} DIVERSIDADE SEXUAL E POLÍTICA NACIONAL DE SAÚDE MENTAL - DUARTE, M. J. O. \}

que envolve, necessariamente, a garantia do acesso aos serviços de saúde. $O$ acesso aos serviços de saúde implica na revisão e operacionalização de formação dos profissionais que atuam nessa política pública e em seus diversos serviços, os quais, em grande parte, reproduzem os discursos hegemônicos estereotipados e discriminatórios que, relacionados particularmente ao campo da saúde mental, fragilizam a possibilidade de uma atenção e um cuidado qualificados à população LGBT.

Neste sentido, é necessário ressaltar que mediante as políticas oficiais para LGBT no campo da saúde, mediadas pelos documentos governamentais e pela esfera do controle social, há muito que se construir quanto ao trato com questões rela-cionadas ao sofrimento e aos direitos desse segmento populacional. Tal segmento foi por anos e anos discriminado, e os efeitos do preconceito por orientação sexual e identidade de gênero, excluídos como determinações sociais do processo saúdedoença. Por isso mesmo, hoje, a partir de sua manifestação como sujeito coletivo e social, através da sua organização como movimento social, tece suas demandas e suas redes e faz a publicização da sua luta pela cidadania e pela saúde, como direito de todos/as e dever do Estado.

Desta forma, cabe ressaltar que os direitos humanos e as políticas públicas LGBT, a partir da constituição de sua governabilidade, oficialmente, têm como pre-missa eliminar a discriminação e a marginalização desses segmentos, em decorrência do esforço de parte do movimento LGBT por ocupar, corroborar e dar a direção nos espaços do poder público. Entre estes esforços podem ser destacados resultados, tais como o Programa Nacional Brasil Sem Homofobia, o Plano Nacional de Promoção da Cidadania e Direitos Humanos LGBT e a Política Nacional de Saúde Integral de LGBT. No entanto, mesmo o Estado reconhecendo essa necessidade, podemos afirmar que essa resposta foi dada a partir da demanda dos movimentos LGBT organizados em suas reivindicações por direitos, cidadania e políticas públicas específicas.

Destaca-se que a luta por direitos e cidadania LGBT não se restringe a ela mesma, mas é orgânica à luta por uma sociedade sem opressões em todos os níveis e, em particular, ao desenvolvimento livre da sexualidade, dos corpos e dos desejos. É necessário ainda, portanto, que esta pauta - promover a defesa dos direitos de LGBT na luta contra as opressões, incluindo a equidade de direitos e benefícios civis, previdenciários, trabalhistas, sociais e humanos, bem como a livre manifestação afetivo-sexual de LGBT no campo público - esteja presente nos espaços políticos, até que tenhamos a concretização de uma sociedade sem LGBTfobia, em geral, e nos serviços de saúde e saúde mental, em particular.

O meu mundo não é como os outros, quero mais, exijo mais, há em mim uma sede de infinito; sou antes uma exaltada, com uma alma intensa, violenta, atormentada, uma alma que não se sente bem onde está. (Florbela Espanca, "Um Amar Perdidamente"). 
heVistg QIII Pgutg

\} DIVERSIDADE SEXUAL E POLÍTICA NACIONAL DE SAÚDE MENTAL - DUARTE, M. J. O. \}

\section{Referências Bibliográficas}

ARÁN, M; MURTA, D; LIONÇO, T. Transexualidade e Saúde Pública no Brasil. Ciência \& Saúde Coletiva, v. 14, n. 4. Rio de Janeiro. Jul/Ago. 2009.

BARBOSA, R. M.; PARKER, R. (Org.). Sexualidades pelo avesso: direitos, identidade, poder. Rio de Janeiro: IMS/UERJ; São Paulo: Editora 34 Letras, 1999.

BRASIL. CONSELHO NACIONAL LGBT. SECRETARIA ESPECIAL DE DIREITOS HUMANOS DA PRESIDÊNCIA DA REPÚBLICA Texto-Base da 2a Conferência Nacional LGBT. Brasília: Conselho Nacional LGBT da Secretaria Especial de Direitos Humanos da Presidência da República, 2011.

. SISTEMA ÚNICO DE SAÚDE. CONSELHO NACIONAL DE SAÚDE. Relatório final da IV Conferência Nacional de Saúde Mental - Intersetorial. Brasília: Conselho Nacional de Saúde/Ministério da Saúde, 2010a.

. Lei $n$ - 10.216 de 06 de abril de 2001, que dispõe sobre a proteção e os direitos das pessoas portadoras de transtornos mentais e redireciona o modelo assistencial em saúde mental. Brasília: Casa Civil. Subchefia para Assuntos Jurídicos. Publicada no Diário Oficial da União em 09 de abril de 2001. $2010 b$.

. Política nacional de saúde integral de LGBT. Brasília: Ministério da Saúde,

- Plano nacional de promoção da cidadania e direitos humanos LGBT. Brasília: Secretaria Especial de Direitos Humanos da Presidência da República, 2009.

. Resolução n.2 de 6 de dez. 2011: estabelece estratégias e ações que orientam o Plano Operativo da Política Nacional de Saúde Integral de Lésbicas, Gays, Bissexuais, Travestis e Transexuais, no âmbito do Sistema Único de Saúde (SUS). Brasília: Ministério da Saúde, 2011. Disponível em: <http://www.brasilsus.com.br/legislacoes/ gm/110905-2.html>. Acesso em fev. 2012.

BUTLER, J. Problemas de gênero: feminismo e subversão da identidade, Rio de Janeiro: Civilização Brasileira, 2003.

CARRARA, S; RAMOS, S; SIMÕES, J.A.;FACCHINI, R. Política, direitos, violência e homossexualidade: Pesquisa 9a Parada do Orgulho GLBT - São Paulo 2005. Rio de Janeiro: CEPESC-UERJ, 2006.

CARRARA, S.;RAMOS, S. Política, direitos, violência e homossexualidade: 9 a Parada do Orgulho GLBT - Rio 2004, Rio de Janeiro: CEPESC-UERJ, 2005.

DUARTE, M.J O. Movimentos e lutas sociais na saúde: o caso do movimento nacional da luta antimanicomial. Em Pauta: teoria social e realidade contemporânea. Rio de Janeiro: Faculdade de Serviço Social da UERJ, v. 7, n. 25, p. 131 - 149, jul. 2010.

FACCHINI, R. Sopa de letrinhas? Movimento homossexual e produção de identidades coletivas nos anos 90. Rio de Janeiro: Garamond, 2005.

FACCHINI, R; FRANÇA, I. L.;VENTURI, G. Sexualidade, cidadania e homofobia: Pesquisa da 10 a Parada do Orgulho GLBT de São Paulo. São Paulo: APOGLBT, 2007 


\section{hevista all pavtg}

\} DIVERSIDADE SEXUAL E POLíTICA NACIONAL DE SAÚDE MENTAL - DUARTE, M. J. O. \}

FOUCAULT, M. História da sexualidade I: a vontade de saber. Rio de Janeiro: Graal, 1977.

MELLO, L. et al. (Orgs). Políticas públicas para a população LGBT: um mapeamento crítico preliminar. Goiânia: Ser-tão - Núcleo de Estudos e Pesquisas em Gênero e Sexualidade da FCS/UFG, 2010. Disponível em <http://www.sertao.ufg.br/politicaslgbt/índex>. Acesso em 19 maio 2011.

OKITA, H. Homossexualismo: da opressão à libertação. São Paulo: Proposta Editorial, 1981.

PERES, W. S. Travestis, cuidado de si e serviços de saúde: algumas reflexões. In: COSTA, H. et. al. (Orgs) Retratos do Brasil homossexual: fronteiras, subjetividades e desejos. São Paulo: Edusp, Imprensa Oficial do Estado de São Paulo, 2010, p 303 319.

PRINCÍPIOS DE YOGYAKARTA. Princípios sobre a aplicação da legislação internacional de direitos humanos em relação à orientação sexual e identidade de gênero. Disponível em: <http://www.clam.org.br/pdf/principios_de_yogyakarta.pdf>. Acesso em 23 maio 2011.

SEFFNER, F. "Composições (com) e resistências (à) norma: pensando corpo, saúde, políticas e direitos LGBT". In: COLLING, L. (Org.) Stonewall $40+$ o que no Brasil? Salvador: Edufba, Coleção Cult n. 9, p. 57 - 78, 2011.

VENTURI, G. et al. (Org.). Diversidade sexual e homofobia no Brasil: intolerância e respeito às diferenças sexuais. São Paulo: Fundação Perseu Abramo, Fundação Rosa Luxemburg Stiffung, 2009.

Recebido em 20 de agosto de 2011

Aceito para publicação em 15 de dezembro de 2011 